\title{
STUDY OF DEFORMATIONS WITHIN ICE SHEETS DUE TO BOTTOM UNDULATIONS BY MEANS OF RADIO ECHO-SOUNDING
}

\author{
By S. OvergaARD
}

(Electromagnetics Institute, Technical University of Denmark, DK-28oo Lyngby, Denmark) and $\mathrm{K}$. RASMUSSEN*

(Geophysical Isotope Laboratory, University of Copenhagen, Haraldsgade 6, DK-2200 Copenhagen N, Denmark)

ABstract. In order to test the theory of glacier flow over bedrock undulations presented by S. J. Johnsen, K. Rasmussen, and N. Reeh in the accompanying abstract, data from the E.G.I.G. and the Dye-3 flow lines on the Greenland ice sheet have been analysed. The data comprise surface profiles measured by conventional techniques, and ice thicknesses and depths of internal isochronic layers obtained by the Technical University of Denmark by means of radio echo-soundings.

Using power spectra of surface and bottom undulations, the transfer function has been calculated in sections with fairly uniform ice thickness and expected magnitude of the transfer function. The noise generated by measurement and digitalization has been estimated. At selected locations the damping of the amplitude of internal layer undulations has been analysed as a function of distance above the bottom.

In essential agreement with the theory of Johnsen, Rasmussen, and Reeh, the results show definite changes of the transfer function and the damping along the E.G.I.G. flow line, presumably due to varying velocity profile.

\footnotetext{
* Present address: Geographical Institute, University of Copenhagen, Haraldsgade 68, DK-2 Ioo Copenhagen,
enmark.
} 